
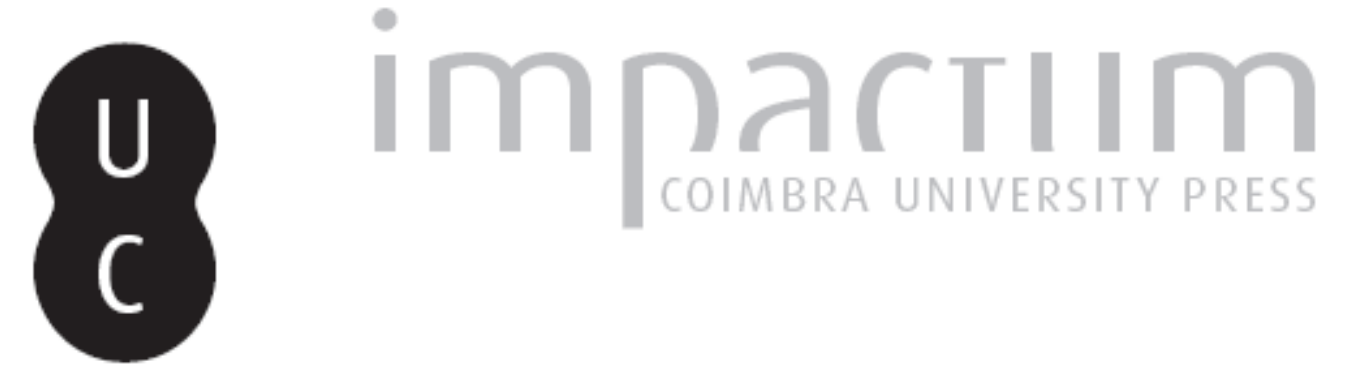

\title{
Aquiles e Ájax: a 'Poiesis' da alteridade na Ânfora de Exéquias
}

\author{
Autor(es): $\quad$ Figueira, Ana Rita
}

Publicado por: Centro de História da Universidade de Lisboa

URL persistente:

URI:http://hdl.handle.net/10316.2/44037

DOI:

DOI:https://doi.org/10.14195/0871-9527_26_5

Accessed : $\quad$ 26-Apr-2023 14:17:11

A navegação consulta e descarregamento dos títulos inseridos nas Bibliotecas Digitais UC Digitalis, UC Pombalina e UC Impactum, pressupõem a aceitação plena e sem reservas dos Termos e Condições de Uso destas Bibliotecas Digitais, disponíveis em https://digitalis.uc.pt/pt-pt/termos.

Conforme exposto nos referidos Termos e Condições de Uso, o descarregamento de títulos de acesso restrito requer uma licença válida de autorização devendo o utilizador aceder ao(s) documento(s) a partir de um endereço de IP da instituição detentora da supramencionada licença.

Ao utilizador é apenas permitido o descarregamento para uso pessoal, pelo que o emprego do(s) título(s) descarregado(s) para outro fim, designadamente comercial, carece de autorização do respetivo autor ou editor da obra.

Na medida em que todas as obras da UC Digitalis se encontram protegidas pelo Código do Direito de Autor e Direitos Conexos e demais legislação aplicável, toda a cópia, parcial ou total, deste documento, nos casos em que é legalmente admitida, deverá conter ou fazer-se acompanhar por este aviso.

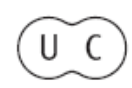




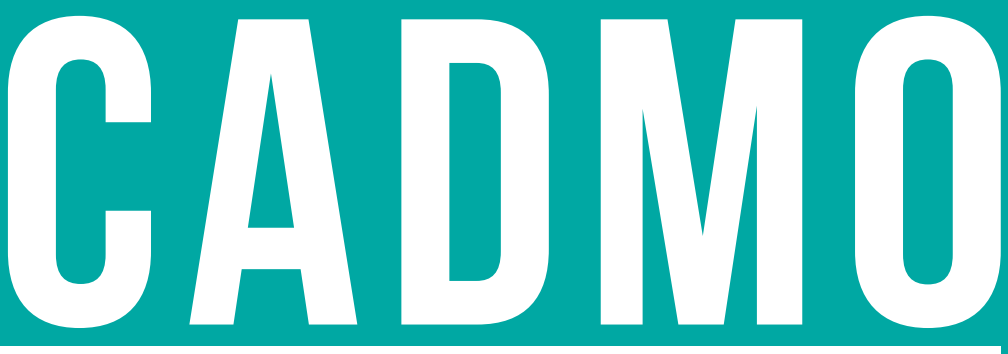

REVISTA DE HISTÓRIA ANTIGA JOURNAL FOR ANCIENT HISTORY

26

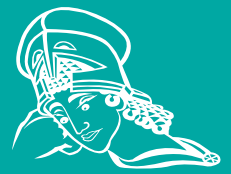

CENTRO DE HISTÓRIA DA UNIVERSIDADE DE LISBOA 2017 


\section{AQUILES E ÁJAX: A 'Poiesis' da alteridade na Ânfora de Exéquias ACHILLES AND AJAX: The 'poiesis' of Alterity in Exekias' Amphora* \\ Ana Rita Figueira Centro de Estudos Clássicos, Faculdade de Letras, Universidade de Lisboa anaritafigueira@campus.ul.pt | (1) https://orcid.org/0000-0002-6246-5247 \\ \begin{tabular}{c|c} 
proposta: \\
submission
\end{tabular}$\quad 07 / 01 / 2017$ | $\begin{gathered}\text { aceitação: 25/09/2017 } \\
\text { acceptance }\end{gathered}$}

\section{Resumo}

Neste ensaio procuramos apresentar uma releitura do vaso de Exéquias e defendemos que o tema de Aquiles e Ájax a jogar um jogo de dados alude à alteridade e ao tempo. Procuramos também apontar o contributo de conceitos literários para esta revisão.

\section{Palavras-chave}

Cerâmica Grega |Aquiles | Ájax | Tempo | Alteridade.

\section{Abstract}

This essay aims to present a rereading of Exekias' vase showing Achilles and Ajax playing a

* Agradeço aos árbitros e aos editores as sugestões que me orientaram nesta revisão.

Este estudo foi iniciado no âmbito do apoio financeiro da Universidade de Lisboa (BAD2015) e foi concluído com o apoio financeiro da Fundação para a Ciência e a Tecnologia (SFRH/BD/129577/2017). 
board game. We argue that this theme alludes to alterity and time and we explain how some literaly concepts are key to our rereading.

\section{Keywords}

Greek Pottery | Achilles |Ajax | Time | Alterity

\section{Abordagens anteriores}

A bibliografia crítica tem reunido objectos que mostram temas semelhantes e investiga possíveis razões para a preferência de um período por uma determinada temática. O período em que surgiu o tema de Aquiles e Ájax a jogar um jogo de dados (ver fig. 1) coincide supostamente com a distracção de parte do exército ateniense, que estando ocupada com o jogo, teria sido surpreendida pelas tropas de Pisístrato, que regressava pela segunda vez a Atenas. A explicação é coerente, porque este regresso é um facto histórico e aquela distracção é possível, apesar de não ser uma certeza. ${ }^{1}$ As fontes literárias também não apontam paralelos, por isso considera-se que Exéquias terá inventado este tema.

Aquela proposta de Boardman sugere por um lado que a imagem é um artefacto produzido no espaço e no tempo ${ }^{2}$ e, por outro lado, indica que independentemente de referenciar um acontecimento, a imagem documenta uma percepção da época que a produziu. Interessa-nos, então, rever o possível significado da temática do jogo associada àqueles heróis.

O jogo sugere, de facto, distracção, noção que inclui as acepções de 'recreio' e de 'concentração do espírito'. É, por isso, uma ocupação seriíssima, uma vez que favorece o reposicionamento do homem educado, estimulando a reflexão, e sendo ainda utilíssimo à argumentação e à audição do outro. Regressando à noção 'distracção', compreendêmo-la como distanciamento do hábito (ethos), como indicam, na imagem, os guerreiros que não estão a combater (ver fig. 1).

1 Boardman 1978.

2 Aguiar e Silva 1991, 34. 
A composição mostra ainda imagens alusivas ao caos desenhadas nos escudos dos heróis, opção que abre um recorte dionisíaco, radicando o jogo no caos e na desordem. Porém, o jogo alude, também por isso, ao tempo e à necessidade de tempo, como, aliás, mais tarde Platão sugere ao iniciar uma reflexão sobre a educação com a referência a Momo, filho da Noite. ${ }^{3}$

A seriedade das expressões, a gravidade das posturas e o tema do regresso (nostos), representado na outra face da ânfora, parecem senão reafirmar aquele juízo. A imagem oferece, então, um discurso autónomo, ao apelandar ao olhar do observador mediante um momento de estranhamento ${ }^{4}$ - porque os heróis, em princípio, nunca teriam sido vistos assim - o que presumivelmente contribui para o estímulo do debate entre os observadores. Esta novidade sugere uma expressão de autoria, que legitima definir 'autor', como alguém que compõe objectos com discurso próprio. Por isso a imagem, tal como a obra literária pode entender-se como sendo autónoma, mas diferentemente desta, enuncia ao invés de narrar. Esta diferença é decisiva, porque no caso da narração, o leitor ou o ouvinte tentam acompanhar uma sequência. Pelo contrário, diante da imagem, o observador pode escolher o trilho visual e regressar a cada ponto inúmeras vezes.

Observa-se, assim, um preceito na construção da imagem, que orienta o olhar, mas as possibilidades da imagem excedem as da narração, no que diz respeito àquelas rotas. ${ }^{5}$ Este detalhe estimula a liberdade interpretativa do observador, cujo olhar ao convergir com a imagem gera plenitude semântica. Neste sentido, pretendemos com este estudo rever aquela especulação e mostrar que o observador tem, de facto, liberdade, mas condicionada.

Esta ânfora de Exéquias está amplamente estudada, ${ }^{6}$ estando disponível informação suficiente para distinguir o artefacto quer como objecto artístico semanticamente autónomo, quer como potência discursiva com voz própria, como sugere a inscrição sobre a face A: Exekias epoiese me ('Exéquias fez-me').

\footnotetext{
Pl. R. 604c, 487c apud Rocha Pereira, 2010 468, 271.

Arist. 1458a, 18-34 apud Valente 2011, 87.

Giuliani 2014, 6-8.

Boardman 1978; Woodford 2003; Moignard 2015; Mackay 2016.
} 


\section{Distinções de Aquiles na Lenda, na Ilíada e na Odisseia}

A lenda de Aquiles é uma das mais antigas. ${ }^{7}$ Filho do mortal Peleu e da ninfa Tétis, Aquiles descende em linha directa de Zeus, ligando-se a Témis por parte de seu avô, Éace, um dos juízes do Hades, o mais justo de todos os Gregos. Aquiles foi educado por um filho de Crono, o centauro Quíron, que o instruiu na arte da lira e da medicina. O herói relaciona-se cedo com o papel de personagem, ${ }^{8}$ máscara que, diferentemente de Ulisses é incapaz de subordinar à sua vocação, como sugere o episódio resultante da profecia de Calcas. Relata aquele episódio que Tróia poderia unicamente ser tomada pelo filho de Peleu, que morreria ao fazê-lo. Tétis veste-o de rapariga e envia-o para a ilha de Ciros para ser educado entre as filhas do rei. Aquiles defende-as do ataque de Ulisses, revelando a sua identidade.

$\mathrm{Na}$ Ilíada, a cólera do herói é desencadeada por questões de injustiça, ${ }^{9}$ nomeadamente por Agamémnon lhe retirar o seu prémio de guerra. O sofrimento extremo e injustificado, como a morte de Pátroclo, ${ }^{10}$ define outra dimensão da cólera de Aquiles, que se manifesta em acções desregradas, como o arrastamento do corpo de Heitor, ${ }^{11}$ ocorrências que intuem a violência como consequência da impotência da razão.

$\mathrm{Na}$ Ilíada Aquiles vive conflitos gerados pela tensão entre a ética ${ }^{12}$ e os acontecimentos que a desafiam. A deusa Atena aparece como alteridade superior, de muita prudência, polyboulos, e de muito engenho, polymetis, que o refreia. O apelo de Príamo ${ }^{13}$ humaniza o herói e desperta-o também para a alteridade, reposicionando-o relativamente à universalidade do sofrimento do destino.

Diferentemente, a Odisseia ${ }^{14}$ menciona a disputa pelas armas de Aquiles, episódio que referencia alegoricamente a noção 'personagem', indicando a pugna pela posse da construção de si como ‘outro’, o que alude à máscara como condição

7 Grimal 1992.

8 Esta noção pressupõe particularidades psicológicas, morais e socioculturais, que no período considerado são unicamente pressentidas e nunca definidas. Todavia, o termo evoca a noção de o mesmo se reinventar como outro, sugerindo a centralidade do plano ficcional na vida empírica.

9 Il. $9.311-429$.

10 Il. 16.820, 18.22.

11 Il. $24.15-18$

12 Il. 9.311-429.

13 Il. 23.486-506.

14 Od. 24.36-94. 
suficiente para obtenção de glória.

Os Gregos ergueram-lhe um túmulo ${ }^{15}$ junto ao mar e Tétis conduziu o seu corpo até à Ilha Branca, onde o herói teria continuado a viver. Plutarco ${ }^{16}$ refere a devoção cultual de Alexandre Magno por Aquiles, seu modelo de vida. A acção justa e a genuinidade do herói podem sustentar aquela preferência. De facto a deposição das armas, o retiro na tenda e a entrega à canção ${ }^{17}$ idealizam uma questão pública, mostrando a sua dimensão privada e individual, problematizando-a.

A morte de Aquiles sugere, por isso, um desajustamento total, panahorios, ${ }^{18}$ em relação ao tempo cronológico e à ética social. Aquele desencontro está patente na fidelização à transparência de carácter ${ }^{19}$ e ao sentido de justiça, que o exorta a rebelar-se contra Agamémnon. ${ }^{20}$ Podemos notar naquelas afinidades a ligação aos ensinamentos ancestrais, e podemos também observar a distanciação relativamente aos seus coevos, que agem para a solução imediata e não para o seu questionamento, como Ulisses, e também relativamente aos deuses, imortais e, por isso indiferentes àquelas questões.

Assim Aquiles surge superior aos mortais e inferior aos deuses, diferença que o aponta como memória para ambas. O culto do herói está vinculado ao luto ${ }^{21} \mathrm{em}$ diversas regiões, ${ }^{22}$ o que robustece aquele julgamento e mostra como História e mito se mesclam. As fontes literárias mencionam relatos de marinheiros que alegavam ter escutado o tinido das armas e à noite os sons de taças e de cantos, ou mesmo de ter visto Aquiles ${ }^{23}$ e as moedas, ${ }^{24}$ da época romana, identificam Alexandre Magno com Aquiles. ${ }^{25} \mathrm{~A}$ literatura não testemunha a 'verdade', mas sugere a indistinção entre universos, revelando a centralidade da noção 'personagem' para a concepção da vida empírica.

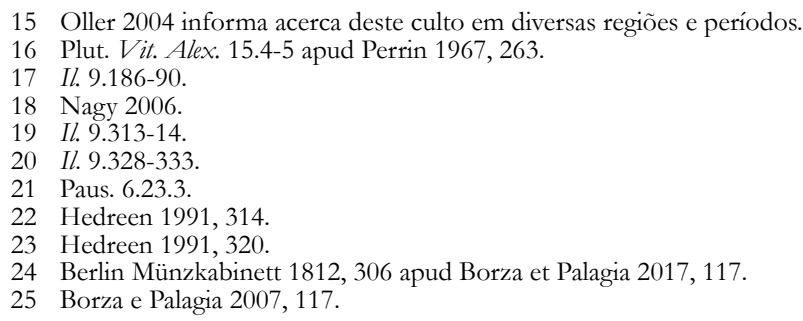




\section{Estudo de Caso - aspectos gerais}

Conhecem-se cerca de cento cinquenta representações ${ }^{26}$ deste tema em vasos de figuras-negras e de figuras-vermelhas. $\mathrm{O}$ jogo ocupa a posição central em todas.

Salientam-se duas grandes teses sobre esta figuração. A primeira defende que se trata de uma pausa durante a guerra, alusiva à negligência dos heróis Aquiles e Ájax relativamente aos seus deveres. A segunda assenta no jogo, que por combinar sorte e perícia, ${ }^{27}$ motiva alguns autores a identificar uma metáfora para designar as forças invisíveis que governam a vida humana. As principais variações mostram os heróis sozinhos, ${ }^{28}$ com observadores,${ }^{29}$ armados, entre mulheres cobertas com mantos; ${ }^{30}$ outros incluem Atena ${ }^{31}$, Atena e guerreiros, ${ }^{32}$ aves $^{33}$ e plantas. ${ }^{34} \mathrm{~A}$ direcção do olhar dos jogadores indica que estão absorvidos no jogo, ${ }^{35}$ o que sugere que a deusa da polis, tal como o observador, não é vista pelos jogadores, mas, à semelhança daqueles, assiste à cena. A maior parte destas reinvenções identifica os heróis por escrito e menciona a sorte (tyche) que lhes coube: Aquiles diz tesara (quatro) e Ájax diz tri [a] (três). Estas inscrições estão posicionadas junto da boca dos heróis, entregando-lhes a palavra, à semelhança de uma banda desenhada. Podemos, portanto, distinguir um enunciado que o observador deve articular, produzindo uma história. Neste sentido, a imagem também é anunciativa, porque evoca o passado (heróico) no presente (da construção do eikeon), para aludir ao futuro (a confluência com o olhar do observador), esbatendo as fronteiras entre o plano ficcional e o plano não ficcional.

Por exemplo, a opção de escrever os nomes das figuras no caso genitivo (Achilleōs) sugere em primeiro lugar que o observador deve fazer uma comparação com Aquiles e, em segundo lugar, favorece a identificação de uma ética de

26 Boardman 1978, 18; Woodford 1986, 61; Mariscal 2011, 394.

27 Beazley, 1986, 60.

28 LIMC 1981a, “Achilleus": 391-92, 394-95, 397, 399, 421; Berlin, Antikensammlung 3267; London, British Museum 1836.2-24.133.

29 E.g. New York, market, Royal Athena 340562; LIMC 1981a, “Achilleus": 398

30 E.g. Copenhagen, Thorvaldsen Museum: H512, face b.

31 A repetição tem sido designada 'fórmula visual' (Mariscal 2011, 394).

32 E.g. Paris, Musée du Louvre: F299.

33 E.g. LIMC 1981a, "Achilleus": 398.

34 E.g. LIMC 1981a, "Achilleus": 405, 408, 410-11, 425-26.

35 E.g. LIMC 1981a, “Achilleus": 402-5, 408, 420; New York (NY), Metropolitan Museum 62.11.2. 
construção de personagens, a partir dos heróis míticos. Esta relação paradigmática leva a pressupor que, na época, se poderia ter acreditado na existência histórica de Aquiles, como já referi. Mas, independentemente desta possibilidade aquela sintaxe indica ao observador que aquilo que está a ver é ficção. Este ponto de vista é duplamente importante, porque mostra não só a centralidade da ficção para a reflexão sobre o mundo, mas também parece convidar o observador para um jogo de reposicionamento. Assim a comparação com os heróis justifica-se, porque a sua história reflecte aquele jogo. A revisão do posicionamento em articulação com a equação de contrários são justamente preocupações filosóficas deste período, que podemos mencionar para fortalecer aquele julgamento. ${ }^{36}$

\section{Descrição da imagem}

O lado A da ânfora mostra um painel central que acompanha a curvatura do bojo. Duas figuras masculinas estão sentadas em bancos cilíndricos, uma em frente à outra. No meio de ambas, uma mesa, num plano inferior aos assentos, referencia o centro da ânfora. Atrás de cada homem está um escudo, pretensamente encostado à parede, como sugere o posicionamento nas extremidades laterais do receptáculo.

A figura que a fotografia mostra à esquerda enverga uma armadura composta pelos seguintes elementos: um elmo encimado por uma grinalda encarnada, uma cota de malha em volta do torso e um manto de tecido. Sobre este estão inscritos motivos florais e formas geométricas, nomeadamente o meandro, o triskelion, o tetraskelion, entre outras, definidas com um traçado esmerado, semelhante a um bordado. As pernas estão protegidas por cnémides, os braços e os pés estão nus. Uma cabeça de leopardo está inscrita sobre o ombro direito e entre este e o cotovelo está desenhada uma forma curva, também repetida nas coxas. A mão esquerda segura duas lanças com as pontas viradas para cima. O escudo atrás desta figura é oval, com recorte lateral (beócio) e tem representada a cabeça de um sátiro, uma serpente e um leopardo. 
O homem sentado do lado direito tem a testa emoldurada por caracóis e uma fita segura-lhe o resto do cabelo no cimo da cabeça. A armadura é idêntica à do guerreiro que está à sua frente, diferindo deste nos seguintes aspectos: o elmo está sobre o escudo atrás de si, e não sobre a cabeça, com a parte da frente virada para a parede. $\mathrm{O}$ braço não tem adornos ou decorações. O escudo mostra uma Górgona.

A inclinação do torso, as cabeças baixas e o olhar focado no tabuleiro indicam concentração. Os braços, em diagonal, acompanham o gesto activo dos dedos. As pernas estão colocadas numa posição que lhes possibilita erguerem-se rapidamente, o que sugere uma atitude de alerta, que é corroborada pelas lanças que seguram com a mão disponível. Schneider ${ }^{37}$ nota que as lanças formam um triângulo invertido, onde se incluem diversas diagonais invisíveis, que unificam a composição e acentuam a posição central das cabeças, aludindo ao pensamento.

As figuras parecem iguais, mas pequenos detalhes indicam que não é assim. Duas inscrições orientam o leitor, ${ }^{38}$ identificado Aquiles, à esquerda e Ájax, à direita, o que é particularmente significativo não só por se tratar dos dois melhores Aqueus, mas também devido ao facto de Ájax raramente ser representado, apesar de Exéquias lhe dedicar particular atenção, possivelmente justificada pelo culto deste herói em Salamina, onde o pintor nasceu. ${ }^{39}$ Um número pouco expressivo de especialistas defende que a articulação daqueles heróis com jogo - que combina estratégia e sorte, como entende unanimemente a bibliografia crítica - indica a negligência dos guerreiros, que assim perigam a vida de todos, por se terem deixado absorver pelo jogo. O gesto e a colocação corporal mostram que a pintura não aponta simplesmente para uma pausa durante a guerra. Vejamos outras indicações que sugerem algo mais.

A mesa de jogo está ao centro da imagem. Aquiles ocupa quase todo o banco e tem o tronco ligeiramente inclinado sobre a mesa de jogo. O pé direito assenta completamente sobre o chão, e o esquerdo está encostado ao banco, com a ponta apoiada no chão, como se o guerreiro estivesse pronto a erguer-se para combater. O gesto flexível mas firme da mão que joga o dado e o olhar atento, mas não

37 Schneider 1968, 386.

38 Stansbury-O'Donnell 2006.

39 Moore 1980, 417-34. 
distraído pelo jogo, é sugerido pela linha curva ligeira e estreita da sobrancelha e o preenchimento da cavidade ocular, que mostra o olho centrado.

Diferentemente, Ájax senta-se à beira do banco, mostra uma curvatura acentuada no torso, os pés não estão apoiados no chão e a linha diagonal das lanças sobrepõe-se ao braço direito, não assentando no chão. A cor branca da cavidade ocular salienta o olhar semicerrado, que o traço cheio e arqueado da sobrancelha enfatiza, indicando lamento ${ }^{40}$ e sugerindo tensão. Esta atitude compromete a atenção do guerreiro ao ambiente que o circunda e a colocação corporal compromete-lhe o equilíbrio.

Os traços negros salientam a expressão, conferindo também emoção às figuras e o gesto aponta aspectos enunciadores da narrativa que o observador deverá reconstruir. Os escudos desempenham um papel determinante na revisão que propomos. A pintura nos vasos não é simbólica, mas os seus signos, como exemplifica o escudo, indicam semânticas possíveis. Ora, este objecto do quotidiano do guerreiro serve para gerar a ilusão de protecção na guerra e para transportar o seu corpo. Por isso, podemos ver naquele objecto um signo alusivo à alteridade, presente em díades como 'troféu-preço de sangue', 'vida-morte', 'eu'-'outro'.

Assim sendo, o escudo de Aquiles mostra um sátiro, figura do tíaso, sensível aos prazeres e à excitação, amante do vinho, da música, da dança e da companhia das ménades, referenciando a dimensão dionisíaca. O segundo elemento, uma serpente, alude ao ctonismo e sugere o presságio, o bem e o mal, a vida e a morte, a vigília e a vingança. A serpente muda a pele, indicando por um lado a renovação e o caos e, por outro lado civilização, orientação e profecia. Está ainda associada a Hera, a deusa da hora, que preside àquilo que acontece na hora. Distingue também Atena e Deméter, deusa ctónica. ${ }^{41} \mathrm{O}$ terceiro elemento, um leopardo ou uma pantera, evoca Dioniso.

O escudo de Ájax, mostra a cabeça de Medusa, a única mortal das três górgonas. A morte, o impensável e o indizível - e também a esterilidade e a repulsa - singularizam esta criatura compósita, que denota a alteridade absoluta, ${ }^{42}$ para a

40 A linha dupla que a forma foi notada noutros trabalhos de Exéquias, onde está associada a expressões de lamento (Moore 1980, 419 n. 12.)

41 Belfiore 2010.

42 Paradiso 1992. 
qual Ájax está de costas.

A mitologia mostra Perseu vitorioso contra a Medusa, petrificada ao ver-se reflectida sobre o seu escudo, e a Ilíada ${ }^{43}$ reinventa o cosmo no escudo de Aquiles. Nesta imagem identificamos a síntese daquelas memórias, que são mostradas de uma maneira totalmente nova. Como podemos, então, interpretar a cena?

Junker ${ }^{44}$ identifica uma metáfora do destino que pesa sobre os homens, e refere a alegada existência de um poema, hoje perdido, que contava que o jogo distraiu os heróis, que não ouviram o som da trompeta e, em consequência, o seu campo de batalha foi invadido. Porém, tal poema, a ter existido, contradiria a lenda, que é explícita quanto à impossibilidade de Aquiles reprimir a sua vocação guerreira. O tema da guerra e do jogo viabiliza esta leitura, salientando a vulnerabilidade do homem às mãos do destino, manifestado no antagonismo entre a demanda de glória e o perigo de morte a que conduz. O guerreiro, como metáfora do homem, encontra-se, portanto entre a sedução e a petrificação, como sugerem os escudos dos dois heróis. Os dados sobre a mesa de jogo conferem verosimilhança à composição, aproximando vida e morte, pois repetem o costume ateniense, contemporâneo desta pintura, de colocar dados nas sepulturas.

Observamos, então, nesta pintura de Exéquias uma equação entre a tyche e o kleos do herói (conduta heróica). De facto, a organização dos elementos legitima esta leitura. Opções como a composição em espelho, sugerida por todos os elementos que integram a imagem, formam uma unidade de contrários, mostrando continuamente o sujeito como outro, dimensão que as formas geométricas reforçam, aludindo à repetição perpétua. As ligeiras diferenças entre as duas figuras masculinas mesclam, à maneira homérica, elementos da vida empírica e do imaginário. Assim, a armadura evoca um hoplita e as saliências sob o manto aferem realismo à cena. $\mathrm{O}$ quadro de nostos do lado $\mathrm{B}$, por representar os gémeos que partilham a vida para que um deles não morra, alude à acção do outro como única garantia de sobrevivência, evocando poeticamente os hoplitas, cidadãos masculinos com elos familiares ou laços de amizade, que comiam e bebiam juntos e, fundamentalmente, estendiam 
estas afinidades ao campo de batalha, onde as suas vidas dependiam da interajuda. ${ }^{45}$ Assim sendo, esta face alude mais directamente à temática do regresso do que a face $\mathrm{A}$, como Boardman ${ }^{46}$, que estuda unicamente esta face, entende. O facto de se tratar de uma cena familiar identificada, onde o papel central dos animais é decisivo (Polideuces, Leda, Cílaro, Castor, Tíndaro), afere à cena dos Dioskouroi uma dimensão universal de 'interesse humano ${ }^{47}$, enfatizada pela opção pela técnica de figurasnegras, que exige mais minúcia. Esta preferência é significativa, porque a técnica de figuras-vermelhas já era habitual, de modo que podemos ver nesta alternativa uma pretensão de detalhe. Realmente a junção de dois heróis que se distinguem entre os Aqueus e que são próximos por laços familiares, acentua a arbitrariedade do destino. Por outro lado, está a fragilidade do instante oportuno (kairos), que decide a sua sorte e, por outro lado este momento alude a forças incontroláveis, que são exteriores ao sujeito, mas que também o integram. Assim sugerem as figuras no escudo de Aquiles (a serpente, o leopardo), cuja dimensão cósmica se repete no corpo do herói, onde está inscrita uma cabeça de leopardo, sobre o deltóide médio.

Diferentemente, metade de uma cabeça semelhante àquela decora a chlamys de Ájax, e não o seu corpo. Esta diferença pode esclarecer o posicionamento dos dois heróis (primeiro e segundo), porque facilita uma explicação para o significado de 'vestir um personagem', nomeadamente, aponta o desajuste consequente daquela acção relativamente àquilo que individualiza este herói. Portanto, a metade da pantera sobre a 'personagem' guerreiro sugere uma acção incompleta que pode explicar a biografia do herói. Na verdade, podemos notar aquela acção definida entre aquilo que individualiza o homem e que é involuntário, e aquilo que é voluntário, mas incompatível com aquilo que o distingue.

As espirais complexificam a figuração, referenciando o movimento perpétuo que flui e reflui. A dupla face da ânfora estimula o movimento, físico e intelectual, porque exorta à interpelação e à torsão, uma vez que não se podem ver ambas as faces simultaneamente, o que desafia o exercício racional e enfatiza a 'acríbia da memória e da glosa' ${ }^{48} \mathrm{~A}$ alteridade sobressai nesta ânfora como realidade ondeante entre a 
glória e a derrota, e mostra-se na alusão ao outro como única garantia daquela. No discurso, a representação de um conjunto ambivalente de elementos é esclarecido em momentos que exigem decisões que envolvem entes queridos, hos philoi, e, de alguma forma exigem um acto performativo, ho ainos. ${ }^{49} \mathrm{O}$ sentido dúplice da noção 'alteridade'- $\mathrm{O}$ outro interior e o 'outro' exterior - exemplifica aquele juízo. Se articularmos a face B com a face $\mathrm{A}$, definimos um movimento circular, que alude à alteridade e a convoca para a resolução de situações que envolvem os que são próximos e queridos, como confirma a vida partilhada dos gémeos (lado B).

Podemos ainda considerar mais dois aspectos para concluir o raciocínio. Este vaso mostra três figuras míticas, que têm em comum, de acordo com a lenda, o facto de todas serem vistas por marinheiros que se aproximam da Ilha Branca. ${ }^{50}$ Por sua vez, a face B complementa a temática da alteridade, uma vez que só regressa quem encontrou na alteridade condições para regressar, à semelhança dos heróis na Odisseia e na Ilíada. No plano não ficcional, a articulação daquelas personagens pode reflectir uma disposição antitirânica, como Boardman notou. ${ }^{51}$ É certo que a imagem se distingue das histórias verbais, tendo em comum com estas o facto de ser também uma construção discursiva, que exige o domínio de técnicas e de competência para as manipular com criatividade e originalidade. Ambas as expressões reinventam personagens, sugerindo semelhanças com heróis fictícios associados a actos fundadores. Estes mostram-se potencialmente mais reais do que se existissem fora da imaginação, ${ }^{52}$ diferentemente dos heróis que se distinguem por combaterem monstros.

\section{Inscrições}

As palavras complexificam a imagem, porque a carga semântica que transportam desencadeia mais perguntas do que respostas. Todavia, tal como a imagem pictórica, também apelam ao observador. Neste estudo pretendemos

49 Nagy 2006, 66.

50 Hedreen 1991, 322.

51 Boardman 1978, 24.

52 Sparkes 1996, 133. 
apontar algumas daquelas questões e sugerir possíveis vias de resposta.

Neste vaso a dupla assinatura ${ }^{53}$ parece reclamar a moldagem do objecto e a concepção da pintura (Exekiasepoiesen; grapsekapoieseme), favorecendo a identificação de uma expressão de autoria. Outra inscrição, entre Ájax e o seu escudo, diz o seguinte: Onetorides kalos (Onetórides é belo). Este exemplo ocasiona uma série de hipóteses, sendo as seguintes as mais relevantes: (a) a frase pode aludir à Atenas de Pisístrato, nomeadamente por evocar um erotismo comum; ${ }^{54}$ (b) Exéquias elogia Onetórides em cinco obras, podendo a inscrição revelar uma afeição pessoal, o que é possível, porque a existência de um tal homónimo está atestada; ${ }^{55}$ (c) as inscrições kalos, durante o período arcaico, não distinguem o estatuto social, unicamente a beleza física. Esta hipótese informa-se na evidência literária, de Homero a Píndaro, sem qualquer conotação ética ou social. ${ }^{56}$

A segunda hipótese oferece mais possibilidades de debate. Esta tese, de Hurwit e de Roisman, é aceitável, mas apesar de este tipo de inscrições ser habitual no séc. VI a.C., Exéquias fez o vaso e a pintura para um cliente. Ora, a inscrição provavelmente só faria sentido se tivesse algum significado para o contexto a que o vaso se destinava, uma vez que os temas são encomendados. ${ }^{57}$ Recentemente Boardman ${ }^{58}$ refere que fidelidade erótica ao nome é possivelmente um fenómeno social, datável entre 550 e 475 a.C., o que reafirma a hipótese (a). Todavia, como o autor alerta noutro lugar ${ }^{59}$ os paralelos com a realidade hoje - como inscrições semelhantes em utensílios, em peças de vestuário - devem ser considerados como moderadores de juízo. Efectivamente o nome Onetórides era muito comum nesta época. Shapiro ${ }^{60}$ informa que o Onetórides de Exéquias poderia ser o irmão de Philon, outro nome que entre 530 e 470 a.C., aparece adjectivado com 'kalos' e Lissarrague $^{61}$ defende que aquela apóstrofe orienta o olhar do observador, mas não interfere com a temática apresentada. Este parecer reforça, portanto, a hipótese

53 Sobre a assinatura nos vasos áticos, veja-se, por exemplo, Cohen 1991 e Manfrini et Strawczynski 2007.

54 Boardman 1978.

55 Hurwit 1992, 261; Roisman 2011, 6.

56 Donlan 1973, 367.

57 Carpenter et al. 2016.

58 Boardman 2003, 111.

59 Boardman 1991, 82.

60 Shapiro 1983, 309 n. 42.

61 Lissarrague $1985,77$. 
de Boardman, que adoptamos, porque o senso-comum facilita a comparação daquele género de frases na publicidade hoje, apontando uma possível via de investigação no futuro.

\section{Observações finais}

Com este estudo pretendemos mostrar que o vaso de Exéquias sobressai como artefacto discursivo autónomo, em que cada face pode contribuir com semânticas alusivas à alteridade, ao destino e ao tempo. Procurámos também apontar alguns conceitos literários que colaboraram com aquela identificação, nomeadamente o conceito 'personagem', que se adequa à compreensão desta obra, e da imagem nos vasos, em geral, como material pedagógico para a construção da realidade social. Naquele processo, a língua verbal articula-se com a expressão icónica, acentuando o esbatimento de fronteiras entre o universo ficcional e o universo não ficcional. 


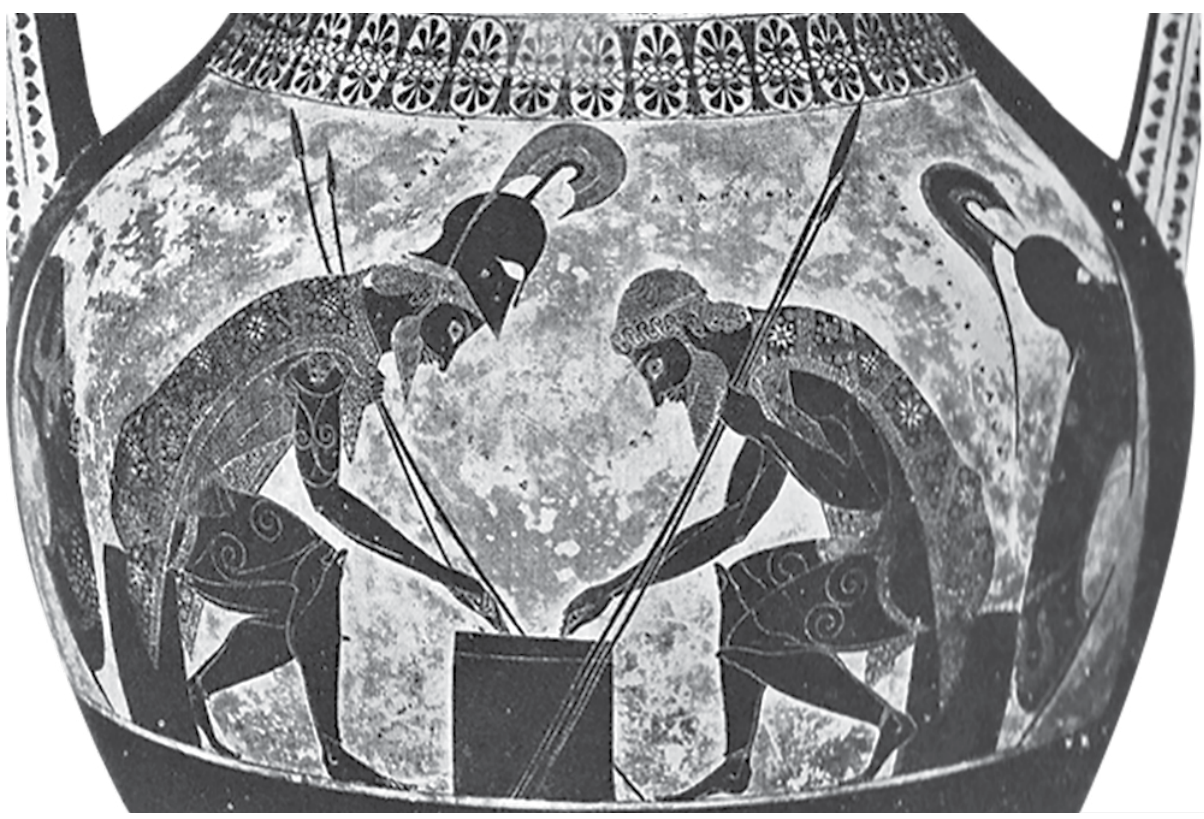

Fig.1: (A) Fotografia: J. Boardman

(A) Aquiles e Ájax jogam sentados, ambos estão identificados, escudos beócios com cabeça de sátiro entre uma cobra e um leopardo (Aquiles) e górgona entre serpentes, elmos (Ájax).

Ânfora. c. 540-530 a.C., Figuras-negras, cerâmica ática. Museo Gregoriano Etrusco, 344 (LIMC 1981b, 397). 



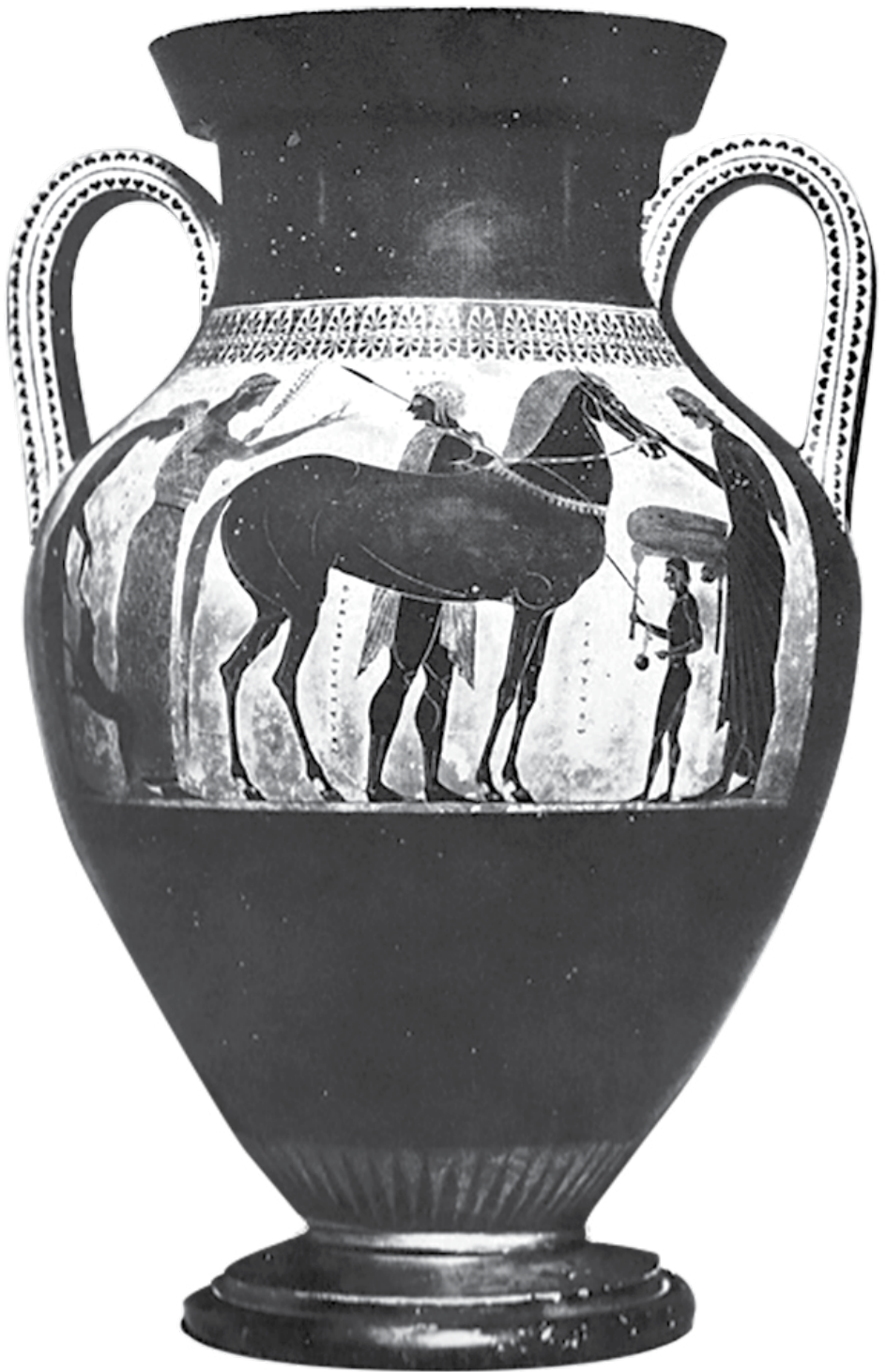

Fig.2: (B) Fotografia: M. Tiverio

(B) Polideuces e Castor chegam a casa. Polideuces inclina-se para saudar o cão, Castor segura as rédeas do cavalo; Leda oferece uma flor a Castor, Tíndaro acaricia o cavalo, um escravo traz um banco com uma peça de tecido dobrada e um aryballos.

Ânfora. c. 540-530 a.C., Figuras-negras, cerâmica ática, Museo Gregoriano Etrusco, 344, (LIMC 1981b, 397). 



\section{BIBLIOGRAPHY}

Beazley, John Davidson. 1986. Development of the Attic black-figure. California: University of California Press.

Belfiore, Jean-Claude. 2010. Dictionnaire des Croyances et des Symboles de l'Antiquité. Paris: Larousse.

Boardman, John Davidson. 2003. “Reading Greek Vases?” OJA 22 (1):109-14. . 1978. "Exekias." AJA 82 (1):11-25.

Borza, Eugene N., et Olga Palagia. 2007. “The Cronology of the Macedonian Royal Tombs at Vergina.” JDAI 122:81-124.

Carpenter, Thomas H., Elizabeth Langridge-Noti, et Mark D. Stansbury-O’Donnell, eds. 2016. The Consumer's Choice. Boston: Archeological Institute of America.

Cohen, Beth. 1991. "The Literate Potter: A tradition of Incised Signatures on Attic Vases.” MMJ 26:49-95.

Donlan, Walter. 1973. “The Origins of kalos kagathos.” AJPh 94:363-74.

Grimal, Pierre. 1992. Dicionário de Mitologia Grega e Romana. Trad. Vítor Jabouille. Lisboa: Difel.

Hawkins, S. 2012. "A Linguistic Analysis of the Vase Inscriptions of Sophilos.” Glotta 88 (1-4):122-65.

Hedreen, Guy. 1991. "The cult of Achilles in the Euxine.” Hesperia 60 (3):303-30.

Hurwit, Jeffrey M. 2015. Artists and Signatures in Ancient Greece. Cambridge: Cambridge University Press. 1992. The Art and Culture of Early Greece. Ithaca: Cornell University.

Johnston, Alan. 2006. Trademarks on Greek Vases: Addenda. Liverpool: University Press.

Jones, W. H. S., trad. 1989. Pausanias. Description of Greece. Vol. 6. London: Heinemann.

Junker, K. 2012. Interpreting the Images of Greek Myth: an introduction. Cambridge: University Press.

Lexicon Iconographicum Mythologiae Classicae. 1981a. Vol. 1, tomo 1. Zürich / München: Artemis Verlag. 1981b. Vol. 1, tomo 2. Zürich / München: Artemis Verlag.

Lissarrague, François. 1985. "Paroles d'Images: Remarques sur le Fonctionnement de l'Écriture dans l'Imagerie Attique.” In L'Écriture II, ed. A. M. Christin, 71-93. Paris: Le Sycomore.

Lloyd, G.E.R. 1964. "The Hot and the Cold, the Dry and the Wet in Greek Philosophy." JHS 84:92-106.

Lourenço, Frederico, trad. 2012. Homero. Odisseia. $9^{a}$ ed. Lisboa: Livros Cotovia. trad. 2010. Homero. Ilíada. $4^{\mathrm{a}}$ ed. Lisboa: Livros Cotovia.

Mackay, E. Anne. 2010. Tradition and originality: A Study of Exekias. London: British Archeological Reports . 1979. "The return of the Dioskouroi: a reinterpretation of the scene on the reverse of the Vatican amphora of Exekias." AJA 83 (4):474-76.

Manfrini, Ivonne, et Nina Strawczynski. 2007. "Une Forge Ambigüe.” Mètis 5:51-90.

Mariscal, Lucia Romero. 2011. “Ajax and Achilles Playing a Board Game: revisited from the literary tradition.” CQ n.s., 61 (2):394-401.

Meunier, M. 1945. La Légende Dorée des Dieux et des Héros. Paris: A. Michel.

Moignard, Elizabeth. 2015. Master of Attic Black-Figure Painting: The Art and legacy of Exekias. London: I. B. Tauris.

Moore, M. B. 1980. "Exekias and Telamonian Ajax.” AJA 84 (4):417-34. 
Nagy, Gregory. 2013. The ancient Greek hero in 24 hours. Cambridge, MA: Harvard University Press.

Neer, R.T. 2002. Style and Politics in Athenian Vase-Painting: the craft of democracy, ca $530-460$ B.C. Cambridge: Cambridge University Press.

Neils, Jenifer. 2007. “Myth and Greek Art: Creating a Visual Language.” In The Cambridge Companion to Greek Mythology, ed. R. D. Woodward, 286-304. Cambridge: Cambridge University Press.

Oller, Marta Guzmán. 2004. Orígenes y Desarrollo del Culto de Aquiles en la Antigüedad: Recogida y Análisis de Fuentes. Tese de Doutoramento. Barcelona: Facultat de Lletres de la Universitat Autònoma de Barcelona.

Paradiso, Annalisa. 1992. "Sur l'altérité grecque, ses degrés, ses états: notes critiques." RHR 1:55-64

Perrin, Bernardotte, trad. 1967. Plutarco. Plutarch's Lives: Demosthenes and Cicero: Alexander and Caesar. Vol. 7. London: William Heinemann.

Rocha Pereira, Maria Helena da, trad. 2010. Platão. República. Lisboa: Gulbenkian.

Roisman, J., et J.C. Yardley. 2011. Ancient Greece from Homer to Alexander: the evidence. Hoboken: John Wiley.

Runciman, W. G. 1990. "Greek Hoplites: Warrior culture, and indirect bias.” Journal of the Royal Anthropological Institute 4:731-52.

Schneider, L. M. 1968. "Composicional and Psychological Use of Spear in Two Vase Paintings by Exekias: A Note on Style." AJA 72:385-86.

Shapiro, H. A.1983. “Epilykos Kalos.” Hesperia 52 (3):305-12.

Aguiar e Silva, Vítor Manuel de. 1991. Teoria da Literatura. $8^{a}$ ed. Coimbra: Almedina.

Sparkes, Brian A. 1996. The red and the black. London: Routledge.

Stansbury-O’Donnell, Mark. 2006. Vase Painting, Gender and Social idendity in Archaic Athens. New York: Cambridge University Press.

Valente, Ana Maria, trad.. 2011. Aristóteles. Poética. $4^{a}$ ed. Lisboa: Fundação Calouste Gulbenkian

Woodford, Susan. 1986. Introduction to Greek, Art. Ithaca and London: Cornell University.

- 2003. The Trojan War in Ancient Art. London: Duckworth. 